\title{
Activity of Fosfomycin in Extended-Spectrum Beta-Lactamases Producing Klebsiella pneumonae from Hospital Acquired Urinary Tract Infections
}

\author{
Ghada El-Saeed Mashaly \\ Medical Microbiology and Immunology Department, Faculty of Medicine, Mansoura University, Egypt \\ Email: ghadamashaly@yahoo.com
}

Received 28 May 2016; accepted 31 July 2016; published 3 August 2016

Copyright (C) 2016 by author and Scientific Research Publishing Inc. This work is licensed under the Creative Commons Attribution International License (CC BY). http://creativecommons.org/licenses/by/4.0/

(c) (i) Open Access

\section{Abstract}

Treatment of hospital acquired urinary tract infections (UTIs) caused by extended-spectrum betalactamases producing Klebsiella pneumonae is a major problem. This organism expresses a high level of resistance to many groups of antibiotics. Fosfomycin is an agent which is recommended for treatment of UTIs caused by ESBLs producers. The aim of this study is to determine the sensitivity pattern of ESBLs producing urinary $K$. pneumonae to antimicrobial agents including fosfomycin in patients of MUHs and determine the prevalence of fosfomycin resistance mediated by plasmid mediated fosfomycin modifying enzymes fosA, fos $B$ and fosA3. Methods: Klebsiella pneumonae urinary isolates were collected from patients with hospital acquired UTIs in Mansoura University Hospitals (MUHs). The susceptibility pattern was determined by Kirby Baur method. Isolates resistant to extended spectrum cephalosporins were tested for ESBLs production by double disc diffusion method. Fosfomycin resistance was determined by broth dilution method. Isolates resistant to fosfomycin were tested for fos $A$, fos $B$ and fos 3 by PCR. Results: A total of 128 ESBLs producing $K$. pneumonae isolates were collected. The highest sensitivity was to imipenem (94.5\%). The lowest was to trimethoprime-sulphamethoxazole (21.8\%). Co-resistance of ESBLs isolates with fosfomycin was $23.2 \%$. Eighteen fosfomycin resistant isolates $(18 / 30)$ were positive to fos $A$. Conclusion: ESBLs producing urinary Klebsiella pneumonae express moderate sensitivity to fosfomycin. Resistance is mainly mediated by plasmid mediated fosfomycin modifying enzymes fos $A$.

\section{Keywords}

Klebsiella pneumonae, Extended-Spectrum Beta-Lactamases, Fosfomycin, Urinary Tract Infection, Plasmid Mediated Resistance 


\section{Introduction}

Urinary tract infection (UTI) is one of the most common hospital-acquired infections (HAIs) especially in developing countries [1]. It represents about $40 \%$ of all hospital acquired infections and is mainly catheter associated [2]. Urinary catheterization for one week or more is associated with development of bacteriuria in at least $25 \%$ of patients with daily risk of $5 \%-7 \%$ [3] [4].

Klebsiella pneumonia is an important cause of these infections. Production of extended-spectrum beta-lactamases (ESBLs) by K. pneumonae restricts the therapeutic options for treatment of infections they cause [5].

Therefore, treatment of ESBLs producing organisms which are resistant not only to cephalosporins but also to other agents like quinolones and aminoglycosides represents a major problem [6]. Co-resistance to these agents is very common, because the resistance genes are located on mobile genetic elements such as plasmids and transposons [7].

This rapid increase in the antibiotic resistance necessitates the implementation of alternative treatment strategies. With the limited availability of novel antimicrobial agents, the reevaluation of older antibiotic agents may show a ray of hope.

Among older antibiotics, fosfomycin appears to be an attractive alternative because of its broad spectrum of activity both against Gram-positive and Gram-negative bacteria and its wide distribution in tissues while retaining high serum level [8] [9].

Fosfomycin was discovered in Spain in 1969 from cultures of Streptomyces. It acts by inhibiting the formation of peptidoglycans during the bacterial cell wall synthesis. This antibiotic is frequently active against multidrug resistant and extremely resistant Enterobacteriaceae [9], and in particular against ESBLs producing Klebsiella pneumonia (ESBLs-KP) [10]. However, many studies showed that fosfomycin resistance increases in areas where it is used widely [11]. Many mechanisms were emerged; the most important is plasmid mediated fosfomycin modifying enzymes [12].

Although fosfomycin is known since more than four decades, few data are available about the effectiveness of this antibiotic against the uropathogens and in its role against ESBLs producing organisms in Egypt.

The current study was therefore performed to provide an insight into the antimicrobial activity of fosfomycin and other common antimicrobials against ESBL-KP isolates from hospital acquired UTI. Also, the role of plasmid mediated $\operatorname{fos} A, \operatorname{fos} B$ and $\operatorname{fos} A 3$ in resistance to fosfomycin in ESBLs producing urinary Klebsiella pneumonae.

\section{Methods}

This study protocol was approved by Ethical committee in faculty of medicine, Mansoura University.

This study was conducted at microbiology department, faculty of medicine, Mansoura University. A prospective study was performed in Mansoura University hospitals between March 2014 and December 2015. Samples were collected from patients hospitalized for longer than 72 hours and developed UTI diagnosed according to the criteria described by the Centers for Disease Control/National Health Service Network (CDC/NHSN) and International Nosocomial Infection Control Consortium (INICC) guidelines [13] [14]. Samples were inoculated on cystine lactose electrolyte deficient (CLED) agar (Oxoid Ltd., Basingstoke, UK) using calibrated loop (10 $\mu$ ). Cultures were incubated for $24 \mathrm{~h}$ at $37^{\circ} \mathrm{C}$, and they were considered positive if colony count $\geq 10^{5} \mathrm{CFU} / \mathrm{ml}$. Klebsiellia pneumonae was identified using the usual identification methods (colony morphology, Gram stained film) and API 20 E (bioMerieux, Marcy-l'Etoile, France) [15] [16]. Antibiotic sensitivity testing was done by standard Kirby-Bauer disk diffusion method, on Mueller-Hinton agar (Oxoid Ltd., Basingstoke, UK). All Klebsiellia pneumonae that were resistant to $3^{\text {rd }}$ generation cephalosporins were tested for ESBLs production by double disc diffusion test. Sensitivity testing of fosfomycin was done by broth microdilution test; the broth was supplemented with glucose-6-phosphate (Sigma Aldrich) to a final concentration of $25 \mathrm{mg} / \mathrm{L}$ as per standard CLSI guidelines [17]. Isolates with intermediate sensitivity were considered as resistant.

Fosfomycin resistance by modifying enzymes was detected by PCR. Plasmid extraction was performed by the alkaline lysis method [18]. Primers used are shown in Table 1. The reactions were performed according to protocol described before [19] using a thermal cycler (MJ Research PTC-100). The amplification conditions were: $94^{\circ} \mathrm{C}$ for $5 \mathrm{~min}, 35$ cycles of denaturation at $93^{\circ} \mathrm{C}$ for $40 \mathrm{~s}$, annealing at $57^{\circ} \mathrm{C}$ for $40 \mathrm{~s}$, elongation at $72^{\circ} \mathrm{C}$ for 40 $\mathrm{s}$ and a final extension of $3 \mathrm{~min}$ at $72^{\circ} \mathrm{C}$.

Statistical analysis was computed on Statistical Package for Social Sciences (SPSS, version 16.00; Chicago, IL, USA). Mean, standard deviation was used for descriptive data. The comparison of categorical data was per- 
formed using the Chi-square test $\left(\chi^{2}\right)$. The difference between groups was considered statistically significant if $\mathrm{p}$ values were $<0.05$.

\section{Results}

A total of 128 ESBLs producing Klebsiella pneumonia were collected from patients with health care associated UTIs in MUHs. Females represent $62.5 \%(80 / 128)$ which was to some extent more than male patients $37.5 \%$ (48/128). Patients age range (18 - 72 years), the mean age was 41.7 with standard deviation 15.3 (Table 2). In the current study, all penicillins, cephalosporins, and aztreonam were reported as resistant in ESBLs producers according to CLSI recommendations [14]. The most effective antibiotics against ESBLs producing Klebsiella pneumonae were imipenem (94.5\%), piperacillin-tazobactam (77.3\%) and cefoperazone-sulbactam (76.6\%). Fosfomycin sensitivity was $76.6 \%(98 / 128)$. The least sensitivity was to trimethoprim-sulphamethoxazole (21.8\%) and ampicillin-sulbactam (24.2). Regarding fosfomycin resistant isolates, the most effective antibiotics were imipenem (98\%), cefoperazone-sulbactam (80.6\%), and piperacillin-tazobactam (74.5\%) (Table 3).

Only 18 fosfomycin resistant isolates harboring fosfomycin resistant gene fosA (60\%). No resistant isolates carries $f o s A 3$ or $f \circ S B$ genes.

No relation was found between resistance to fosfomycin and resistance to other drugs except imipenem and cefoperazone-sulbactam (P value $<0.05)$.

\section{Discussion}

There is a continuous increase in the antibacterial resistance of most bacterial species according to National Nosocomial Infections Surveillance (NNIS) data [23]. The resistance reached to a serious situation that multidrug resistant ESBLs producing bacteria causing severe UTI have been reported in hospital acquired infections [24] [25].

Beta-lactam/beta-lactamase inhibitor combination antibiotics may be effective as a therapy for extendedspectrum beta-lactamases producing Enterobacteriaceae [26].

The current study found that beta lactam-beta lactamase inhibitors combinations generally showed lower sensitivity against ESBL producers Klebsiella pneumonae except for piperacillin-tazobactam (77.3\%) and cefoperazone-sulbactam $(76.6 \%)$.

This low sensitivity is agreed with other reports by Jiang et al. [27] who found sensitivity to ampicillin-clavunlante and piperacillin-tazobactam were $40 \%$ and $60 \%$ respectively. Furthermore, other study by Chen et al. [28] reported the sensitivity to piperacillin-tazobactam in ESBLs producing Klebsiella pneumonae was (74.6\%).

\begin{tabular}{|c|c|c|c|}
\hline Gene & Primer & Size & Reference \\
\hline fos $A-F$ & 5'-ACATATGCTGCAATCACTCAA-3' & \multirow{2}{*}{434} & \multirow{2}{*}{ [20] } \\
\hline fos $A-R$ & 5'-GTGATCAAGCCTCGTCTGAGG-3' & & \\
\hline fos $B-F$ & 5'-ATATGATCAAAGGAATAAATC-3' & \multirow{2}{*}{434} & \multirow{2}{*}{ [21] } \\
\hline$f o s B-R$ & 5'-CATATGAAAATTCATATGAGG-3' & & \\
\hline fos $A 3-F$ & 5'-GCGTCAAGCCTGGCATTT-3' & \multirow{2}{*}{282} & \multirow{2}{*}{ [22] } \\
\hline fos $A 3-R$ & 5'-GCCGTCAGGGTCGAGAAA-3' & & \\
\hline
\end{tabular}

Table 2. Patients' characters.
\begin{tabular}{cc}
\hline Sex & NO (\%) \\
\hline Male & $48(37.5)$ \\
Female & $80(62.5)$ \\
\hline Age & \\
\hline Mean \pm SD (min-max) & $41.7 \pm 15.3(18-72)$ \\
\hline
\end{tabular}


Table 3. Antibiotic sensitivity pattern of fosfomycin susceptible and fosfomycin resistant ESBLs producing Klebsiella pneumoniae isolates.

\begin{tabular}{|c|c|c|c|c|c|c|}
\hline & \multicolumn{2}{|c|}{ Fosfomycin susceptible isolates } & \multicolumn{2}{|c|}{ Fosfomycin resistant isolates } & \multirow{2}{*}{$\begin{array}{c}\text { Total } \\
\text { susceptibility } \\
\text { No }(\%)\end{array}$} & \multirow{2}{*}{$P$ value } \\
\hline & $\begin{array}{c}S \\
\text { No }(\%)\end{array}$ & $\begin{array}{c}\text { NS } \\
\text { No }(\%)\end{array}$ & $\begin{array}{c}S \\
\text { No }(\%)\end{array}$ & $\begin{array}{c}\text { NS } \\
\text { No (\%) }\end{array}$ & & \\
\hline Cefoperazone-sulbactam & $79(80.6)$ & $19(19.4)$ & $12(40)$ & $18(60)$ & $76.6(82)$ & 0.001 \\
\hline Norfloxacin & $42(42.9)$ & $56(57.1)$ & $12(40)$ & $18(60)$ & $54(42.2)$ & 0.8 \\
\hline Gentanicin & $36(36.7)$ & $62(57.1)$ & $16(53.3)$ & $14(46.7)$ & $52(40.6)$ & 0.09 \\
\hline Amikacin & $53(54.1)$ & $45(45.9)$ & $18(60)$ & $12(40)$ & $71(55.4)$ & 0.7 \\
\hline Nitrofurantoin & $40(40.8)$ & $58(59.2)$ & $10(33.3)$ & $20(66.7)$ & $50(39)$ & 0.5 \\
\hline $\begin{array}{c}\text { Trimethoprim- } \\
\text { sulphamethoxazole }\end{array}$ & $19(19.4)$ & $79(80.6)$ & $9(30)$ & $21(60)$ & $37(21.8)$ & 0.2 \\
\hline Amoxacillin-clavulanic & $26(26.5)$ & $72(73.5)$ & $13(43.3)$ & $17(56.7)$ & $39(30.4)$ & 0.1 \\
\hline Ampicillin-sulbactam & $25(25.5)$ & $73(74.5)$ & $6(20)$ & $24(80)$ & $31(24.2)$ & 0.6 \\
\hline Piperacillin-tazobactam & $73(74.5)$ & $25(25.5)$ & $26(86.7)$ & $4(13.3)$ & $98(77.3)$ & 0.2 \\
\hline Imipenem & $96(98)$ & $2(2)$ & $25(83.3)$ & $5(16.7)$ & $121(94.5)$ & 0.008 \\
\hline
\end{tabular}

S: susceptible; NS: non-susceptible.

This decreased efficacy of beta lactam-beta lactamase inhibitors combinations may be due in the presence of a high bacterial load because of high inoculum infections which overcome the effect of beta-lactamase inhibitors [26] [29].

The ESBLs producing bacteria can acquire co-resistance to other classes of antimicrobial agents, such as fluoroquinolones, trimethoprim-sulphamethoxazole, and aminoglycosides, which are used for UTIs frequently [26]. Low susceptibility of these groups was reported in this study $(42.2 \%, 21.8,55.4 \%$, and $40.6 \%)$ to norfloxacin, trimethoprim-sulphamethoxazole, amikacin and gentamicin respectively. This worldwide alarming with the limitation of newer antibacterial agents necessitates the reevaluation of older agents. One of these agent is; fosfomycin which is available as oral and IV [30]. The importance of fosfomycin for treatment of UTIs has been increased due to increased rate of resistance to other agents, good safety, resistance of anaerobic gut flora, and safe use during pregnancy. It is recommended for treatment of ESBLs producing organisms which become a serious problem in health care [6] [31]-[33]. Few studies encounter the resistance to fosfomycin. To our knowledge, the current study is the first study that reports the fosfomycin resistance in ESBL KP in Egypt. The fosfomycin resistance in this study was $23.4 \%$. This resistance rate is similar to that reported before [34] [35]. This result is higher than other results obtained in other studies [26] [36].

Evaluating co-resistance pattern with other antibacterial agents that are used for treatment of UTIs and ESBLs producing organisms was somewhat helpful in predicting fosfomycin resistance. There is no statistical significance for any specific pattern except for imipenem and cefoperazone-sulbactam. This result is consistent with other reports before [34] [37].

So, it can be used properly for treatment of infections by strains resistant to other antibiotics.

Only 18 resistant isolates carry fos $A$ gene, negative result was obtained for fos $A 3$ and fos $B$. This result is similar to other reports which find that $\operatorname{fos} B$ is responsible for the fosfomycin resistance in Gram-positive bacteria like Staphylococci and Enterococci [21] [38] [39]. In addition, this result may reflect the responsibility of mechanisms other than fosfomycin modifying enzymes for the resistance to fosfomycin in ESBLs producing Klebsiella pneumonae. These mechanisms may be chromosomal mutation and fosfomycin degradation [40] [41].

This study has some limitations. First, unavailability of clinical data about patients enrolled in the study. Furthermore, this study represents a report for the sensitivity of fosfomycin in vitro rather than in vivo whereas clinical response to fosfomycin may be different from laboratory result. So, further studies about in vivo results of fosfomycin use for treatment of UTI caused by ESBLs producing Klebsiella pneumoniae are recommended and the effect of patients clinical condition on the response to fosfomycin. 


\section{Conclusion}

Lower rate of resistance was reported to fosfomycin in ESBLs producing Klebsiella pneumonae (23.4\%) compared to other agents like quinolones and aminoglycosides. So fosfomycin is suitable for treatment of UTIs caused by ESBL-KP resistant to other antibacterial agents. Fosfomycin resistance is mediated mainly by plasmid mediated fosfomycin modifying enzymes fos $A$.

\section{Conflict of Interests}

The author declares that there is no conflict of interests regarding the publication of this paper.

\section{References}

[1] Beyene, G. and Tsegaye, W. (2011) Bacterial Uropathogens in Urinary Tract Infection and Antibiotic Susceptibility Pattern in Jimma University Specialized Hospital, Southwest Ethiopia. Ethiopian Journal of Health Sciences, 21, 141-146. http://dx.doi.org/10.4314/ejhs.v21i2.69055

[2] Rüden, H., Gastmeier, P., Daschner, F.D. and Schumacher, M. (1997) Nosocomial and Community-Acquired Infections in Germany. Summary of the Results of the First National Prevalence Study (NIDEP). Infection, 25, 199-202. http://dx.doi.org/10.1007/BF01713142

[3] Maki, D.G. and Tambyah, P.A. (2001) Engineering out the Risk for Infection with Urinary Catheters. Emerging Infectious Disease, 7, 342-347. http://dx.doi.org/10.3201/eid0702.010240

[4] Tambyah, P., Olyszyna, D.P., Tenke, P. and Koves, P. (2010) Urinary Catheters and Drainage Systems: Definition, Epidemiology and Risk Factors. In: Naber, K.G., Schaeffer, A.J., Heyns, C., Matsumoto, T., et al., Eds., Urogenital Infections, European Association of Urology, Arnhem, 523-531.

[5] Gupta, K. (2003) Emerging Antibiotic Resistance in Urinary Tract Pathogens. Infectious Disease Clinics of North America, 17, 243-259. http://dx.doi.org/10.1016/S0891-5520(03)00006-0

[6] Auer, S., Wojna, A. and Hell, M. (2010) Oral Treatment Options for Ambulatory Patients with Urinary Tract Infections Caused by Extended-Spectrum-Beta-Lactamase-Producing Escherichia coli. Antimicrobial Agents and Chemotherapy, 54, 4006-4008. http://dx.doi.org/10.1128/AAC.01760-09

[7] Tsukamoto, N., Ohkoshi, Y., Okubo, T., Sato, T., Kuwahara, O., Fujii, N., Tamura, Y. and Yokota, S. (2013) High Prevalence of Cross-Resistance to Aminoglycosides in Fluoroquinolone-Resistant Escherichia coli Clinical Isolates. Chemotherapy, 59, 379-384.

[8] Michalopoulos, A.S., Livaditis, I.G. and Gougoutas, V. (2011) The Revival of Fosfomycin. International Journal of Infectious Diseases, 15, e732-e739. http://dx.doi.org/10.1016/j.ijid.2011.07.007

[9] Parker, S., Lipman, J., Koulenti, D., Dimopoulos, G. and Roberts, J.A. (2013) What Is the Relevance of Fosfomycin Pharmacokinetics in the Treatment of Serious Infections in Critically Ill Patients? A Systematic Review. International Journal of Antimicrobial Agents, 42, 289-293. http://dx.doi.org/10.1016/j.ijantimicag.2013.05.018

[10] Falagas, M.E., Kastoris, A.C., Kapaskelis, A.M. and Karageorgopoulos, D.E. (2010) Fosfomycin for the Treatment of Multidrug-Resistant, Including Extended-Spectrum Beta-Lactamase Producing, Enterobacteriaceae Infections: A Systematic Review. The Lancet Infectious Diseases, 10, 43-50. http://dx.doi.org/10.1016/S1473-3099(09)70325-1

[11] Oteo, J., Orden, B., Bautista, V., Cuevas, O., Arroyo, M., Martínez-Ruiz, R., Pérez-Vázquez, M., Alcaraz, M., García-Cobos, S. and Campos, J. (2009) CTX-M-15 Producing Urinary Escherichia coli O25b-ST131-Phylogroup B2 Has Acquired Resistance to Fosfomycin. Journal of Antimicrobial Chemotherapy, 64, 712-717. http://dx.doi.org/10.1093/jac/dkp288

[12] Karageorgopoulos, D.E., Wang, R., Yu, X.H. and Falagas, M.E. (2012) Fosfomycin: Evaluation of the Published Evidence on the Emergence of Antimicrobial Resistance in Gram-Negative Pathogens. Journal of Antimicrobial Chemotherapy, 67, 255-268. http://dx.doi.org/10.1093/jac/dkr466

[13] (2013) CDC/NHSN Surveillance Definition of Healthcare-Associated Infection and Criteria for Specific Types of Infections in Acute Care Setting. www.INICC.org

[14] Horan, T.C., Andrus, M. and Dudeck, M.A. (2008) CDC/NHSN Surveillance Definition of Healthcare-Associated Infection and Criteria for Specific Types of Infections in Acute Care Setting. American Journal of Infection Control, 36 , 309-332. http://dx.doi.org/10.1016/j.ajic.2008.03.002

[15] Collee, J.G., Miles, R.S. and Watt, B. (1996) Tests for the Identification of Bacteria. In: Collee, J.G., Marmion, B.P., Fraser, A.G. and Simmons, A., Eds., Mackie \& McCartney Practical Medical Microbiology, 14th Edition, Churchill Livingstone, New York, 131-151.

[16] Chessbrough, M. (1993) Collection, Transport and Examination of Specimens. In: Chessbrough, M., Eds., Medical 
Laboratory Manual for Tropical Countries, Butterworth-Heinemann, Oxford, 100-195.

[17] Clinical and Laboratory Standards Institute (2013) Performance Standards for Antimicrobial Susceptibility Testing. 23rd Informational Supplement, CLSI Document M100-S23, CLSI, Wayne.

[18] Sambrook, J., Fritsch, E.F. and Maniatis, T. (1989) Plasmid Vectors. In: Nolan, C. and Ferguson, M., Eds., Molecular Cloning. A laboratory Manual, 2nd Edition, Cold Spring Harbour, New York, 3-110.

[19] Gray, K.J., Gascoyne-Binzi, D.M., Nicholson, P., Heritage, J. and Hawkey, P.M. (2001) Transmissible Fosfomycin Resistance Markers in Urinary Isolates and Imported Food Stuffs in the UK during 1994 and 1995. Journal of Antimicrobial Chemotherapy, 48, 744-745. http://dx.doi.org/10.1093/jac/48.5.744

[20] Garcia, P., Arca, P., Toyos, J.R. and Suarez, J.E. (1994) Detection of Fosfomycin Resistance by the Polymerase Chain Reaction and Western Blotting. Journal of Antimicrobial Chemotherapy, 34, 955-963. http://dx.doi.org/10.1093/jac/34.6.955

[21] Zilhao, R. and Courvalin, P. (1990) Nucleotide Sequence of the fosB Gene Conferring Fosfomycin Resistance in Staphylococcus epidermidis. FEMS Microbiology Letters, 56, 267-272.

[22] Hou, J., Huang, X., Deng, Y., He, L., Yang, T., Zeng, Z., Chen, Z. and Liu, J.H. (2012) Dissemination of the Fosfomycin Resistance Gene fos $A 3$ with CTX-M $\beta$-Lactamase Genes and $r m t B$ Carried on IncFII Plasmids among Escherichia coli Isolates from Pets in China. Antimicrobial Agents and Chemotherapy, 56, 2135-2138. http://dx.doi.org/10.1128/AAC.05104-11

[23] National Nosocomial Infections Surveillance S. (2004) National Nosocomial Infections Surveillance (NNIS) System Report, Data Summary from January 1992 through June 2004, Issued October 2004. American Journal of Infection Control, 32, 470-485. http://dx.doi.org/10.1016/j.ajic.2004.10.001

[24] Malhotra, V.L., Khandpur, N., Dass, A. and Mehta, G. (2008) Prevalence of Extended Spectrum Beta-Lactamases Producing Clinical Isolates from Patients of Urinary Tract Infection in a Tertiary Care Hospital in Delhi. Journal of Communicable Diseases, 40, 269-272.

[25] Tariq, T.M. (2014) Occurrence of Extended-Spectrum B-Lactamase Producers among Enterobacteriaceae in a Paediatric Tertiary Care Facility in Kabul. Journal of the College of Physicians and Surgeons Pakistan, 24, 530-531.

[26] Harris, P.N., Tambyah, P.A. and Paterson, D.L. (2015) $\beta$-Lactam and $\beta$-Lactamase Inhibitor Combinations in the Treatment of Extended-Spectrum $\beta$-Lactamase Producing Enterobacteriaceae: Time for a Reappraisal in the Era of Few Antibiotic Options? The Lancet Infectious Diseases, 15, 475-485. http://dx.doi.org/10.1016/S1473-3099(14)70950-8

[27] Jiang, Y., Shen, P., Wei, Z., Liu, L., He, F., Shi, K., Wang, Y., Wang, H. and Yu, Y. (2015) Dissemination of a Clone Carrying a fosA3-Harbouring Plasmid Mediates High Fosfomycin Resistance Rate of KPC-Producing Klebsiella pneumoniae in China. International Journal of Antimicrobial Agents, 45, 66-70. http://dx.doi.org/10.1016/j.ijantimicag.2014.08.010

[28] Chen, Y.H., Hsueh, P.R., Badal, R.E., Hawser, S.P., Hoban, D.J., Bouchillon, S.K., Ni, Y. and Paterson, D.L. (2011) Antimicrobial Susceptibility Profiles of Aerobic and Facultative Gram-Negative Bacilli Isolated from Patients with Intra-Abdominal Infections in the Asia-Pacific Region According to Currently Established Susceptibility Interpretive Criteria. Journal of Infection, 62, 280-291. http://dx.doi.org/10.1016/j.jinf.2011.02.009

[29] Paterson, D.L. and Bonomo, R.A. (2005) Extended-Spectrum Beta-Lactamases: A Clinical Update. Clinical Microbiology Reviews, 18, 657-686. http://dx.doi.org/10.1128/CMR.18.4.657-686.2005

[30] Paladin Labs (2007) Monurol Package Insert. Paladin Labs, Quebec.

[31] Pullukcu, H., Tasakan, M., Sipahi, O.R., Yamazhan, T., Aydemir, S. and Ulusoy, S. (2007) Fosfomycin in the Treatment of Extended Spectrum Beta-Lactamase-Producing Escherichia coli-Related Lower Urinary Tract Infections. International Journal of Antimicrobial Agents, 29, 62-65. http://dx.doi.org/10.1016/j.ijantimicag.2006.08.039

[32] Wienke, M., Pfeifer, Y., Weissgerber, P., Marschal, M., Autenrieth, I.B. and Grobner, S. (2012) In Vitro Activity of Tigecycline and Molecular Characterization of Extended-Spectrum $\beta$-Lactamase-Producing Escherichia coli and Klebsiella pneumoniae Isolates from a University Hospital in South-Western Germany. Chemotherapy, 58, 241-248. http://dx.doi.org/10.1159/000339488

[33] Demir, T. and Buyukguclu, T. (2013) Evaluation of the in Vitro Activity of Fosfomycin Tromethamine against Gram Negative Bacterial Strains Recovered from Community- and Hospital-Acquired Urinary Tract Infections in Turkey. International Journal of Infectious Diseases, 17, e966-e970. http://dx.doi.org/10.1016/j.ijid.2013.04.005

[34] Sun, F., Chen, S., Qiu, X., Sun, Y., Feng, W., Chen, J. and Xia, P. (2014) Antibacterial Activity of Fosfomycin against Uropathogens. Chemotherapy, 60, 157-161. http://dx.doi.org/10.1159/000371734

[35] Linsenmeyer, K., Strymish, J., Weir, S., Berg, G., Brecher, S. and Gupta, K. (2015) Activity of Fosfomycin against Extended-Spectrum- $\beta$-Lactamase-Producing Uropathogens in Patients in the Community and Hospitalized Patients. Antimicrobial Agents and Chemotherapy, 60, 1134-1136. http://dx.doi.org/10.1128/AAC.02614-15

[36] Lee, S.Y., Park, Y.J., Yu, J.K., Jung, S., Kim, Y., Jeong, S.H. and Arakawa, Y. (2012) Prevalence of Acquired Fosfo- 
mycin Resistance among Extended-Spectrum $\beta$-Lactamase-Producing Escherichia coli and Klebsiella pneumoniae Clinical Isolates in Korea and IS26-Composite Transposon Surrounding fosA3. Journal of Antimicrobial Chemotherapy, 67, 2843-2847. http://dx.doi.org/10.1093/jac/dks319

[37] Reeves, D.S. (1994) Fosfomycin Trometamol. Journal of Antimicrobial Chemotherapy, 34, 853-858. http://dx.doi.org/10.1093/jac/34.6.853

[38] Etienne, J., Gerbaud, G., Courvalin, P. and Fleurette, J. (1989) Plasmid-Mediated Resistance to Fosfomycin in Staphylococcus epidermidis. FEMS Microbiology Letters, 52, 133-137. http://dx.doi.org/10.1111/j.1574-6968.1989.tb03566.x

[39] Thompson, M.K., Keithly, M.E., Harp, J., Cook, P.D., Jagessar, K.L., Sulikowski, G.A. and Armstrong, R.N. (2013) Structural and Chemical Aspects of Resistance to the Antibiotic Fosfomycin Conferred by fosB from Bacillus cereus. Biochemistry, 52, 7350-7362. http://dx.doi.org/10.1021/bi4009648

[40] Horii, T., Kimura, T., Sato, K., Shibayama, K. and Ohta, M. (1999) Emergence of Fosfomycin-Resistant Isolates of Shiga-Like Toxin-Producing Escherichia coli O26. Antimicrobial Agents and Chemotherapy, 43, 789-793.

[41] Walsh, C.C., McIntosh, M.P., Peleg, A.Y., Kirkpatrick, C.M. and Bergen, P.J. (2015) In Vitro Pharmacodynamics of Fosfomycin against Clinical Isolates of Pseudomonas aeruginosa. Journal of Antimicrobial Chemotherapy, 70, 30423050. http://dx.doi.org/10.1093/jac/dkv221

\section{Submit or recommend next manuscript to SCIRP and we will provide best service for you:}

Accepting pre-submission inquiries through Email, Facebook, Linkedin, Twitter, etc A wide selection of journals (inclusive of 9 subjects, more than 200 journals)

Providing a 24-hour high-quality service

User-friendly online submission system

Fair and swift peer-review system

Efficient typesetting and proofreading procedure

Display of the result of downloads and visits, as well as the number of cited articles

Maximum dissemination of your research work

Submit your manuscript at: http://papersubmission.scirp.org/ 